\title{
Welcome Note
}

This year again the 4th issue of OPUS is published in English and centred around a special topic, digital pedagogy, a methodology that synthesizes the issues of modern education, applied infocommunication, interactive curriculum, online collaboration and media literacy. As a guest editor, Zoltán Szüts, associate professor of Department of Technical Education at Budapest University of Technology and Economics - with contributions from renowned Hungarian researchers - coordinated the edition of an issue.

Only after putting out the call for papers, we found that time had passed. That the idea of digital pedagogy is not a novelty anymore and that has already past and history too. That it consists of best practice, but also of dead ends, in previous ten years, methodologies have been formed, several trends have become popular or disappeared, such as connectivity; flipped classroom; MOOC; virtual and augmented reality; crowdsourcing, and open content development. These are only the major trend to be mentioned that dominated the decade since the publication of Digital Pedagogy with Typotex in 2008.

The core idea behind the current issue was that the teaching and learning process supported by info communication tools and online media has become commonplace and familiar for teachers. Using digital technologies, several instructors have already paved the way for learning and teaching in a tangible universe of virtual, technically determined, info-communication and digital media governed educational space. But just as we got used to technology and this new educational environment, we should stop for a moment and look back. If we do so, we will notice that, in some respects, the traditional methodology is also appreciated. It also means that we should also know when not to use ICT in education. That we should also be aware of its advantages and disadvantages.

The first paper of the issues is written by László Z. Karvalics and its title: Students in Science and Knowledge. According to Karvalics, who is a renowned information society researcher, the time has come to talk about digital initiates rather than immigrants and natives. This new classification could encourage the formation of a new alliance between society, and school, teacher and student. Zoltán Szüts, in his paper A Critical Approach to Digital Pedagogy - A Holistic Methodology in the Information Society seeks a path to digital pedagogy that complements previous educational approaches. The author suggests that over the last three decades, after the emergence of the global digital network, online communication and media has become a vital part of the learning process, and by today it has reached the end of the experimental phase and stepped into productivity phase. But for the methodology to be successful, there are several components digital pedagogy architects must take into consideration. Tibor Koltay, as an expert in digital library studies, presents the issue of data literacy in academia, focusing on basics and pedagogical views: data literacy, applied in academic environments, therefore related to research data, which similarly to other types of data, needs to be managed. Koltay argues that technological advances have created opportunities and threats for the free flow of information in society and raised awareness of the importance of information literacy.

In her paper, Adrienn Papp-Danka reflects on the connections between digital lifestyle, digital citizenship and digital pedagogy. The study centres around the question of how digital citizenship competence can be developed from daily digital life routines. Meanwhile, the role and potential of digital pedagogy to developed digital citizenship competence are discussed.

András Buda states that many are not satisfied with today's education. Some criticize the tools available, others see shortcomings in teacher preparedness, but some also call for a change in the teaching environment. Accordingly, there is a different perception of developments, but everyone 
agrees that digital technology will play a very important role in this process. The study presents the results of a survey that are very useful for instructors who intend to involve info communication technology into their classes. Judit Mihalik has chosen a hot topic, the role of agility in higher education. The author presents the issue through a collaborative research project report and uses a case study approach to show how future-oriented skills can be developed in a higher education subject areas. Presenting a student collaboration project process, it looks at agile in education and explains how a mix of methods and tools have used to facilitate this sort of active learning. The title of the paper published by György Molnár is Digital instruction or the digitalization of instruction in the modern ICT environment. While utilizing the domestic and international trends along with almost 20 years of experience as a teacher and instructor in higher education the author is presenting feedback received from students regarding the application of digital devices, and interactive methodology and technology into education. As an expert in engineer training, Dénes Zarka presents an online collaboration practice for active learning in the visual age through experiences of the VOCAL project. The finding of the paper is to learn on-line collaboration with given tools; a visual learning process is also essential. The real learning efforts and the needs for this visual learning should be researched further in the future. The final paper of the issue is an author by two researchers, Monica Dukić and Júlia Mecséri. The High 5! disability awareness program affects the entire school environment and is also important at the level of individuals as it allows students to become better citizens in the whole society. The authors argue that incorporating the understanding of disability into multicultural education has long-term benefits to students as it provides them with tools that will enable them to understand and embrace elements of diversity in the world.

The issue would not be complete without a review. András Benedek reviews a book published by Zoltán Szúts in 2018 with Wolters Kluwer Publishing House title Online. Regarding to Benedek, in terms of the content of the volume, Online deals with one of the important phenomenon history of the latest century, the story of online communication and media, and mainly offers orientation or intellectual impulses for the reader by providing, often wiki-like, descriptions of thoughts connected to some interrelations and associative titles or essayistic reflections and the introduction and elaboration of the author's opinion on the issue.

We hope that you will find this English issue of Opus et Education attractive and start your expedition into digital pedagogy at the end of 2019.

$\begin{array}{ll}\text { András Benedek } & \text { Zoltán Szüts } \\ \text { editor in chief } & \text { guest editor }\end{array}$

